\title{
The Effect of Genetic Merit and Production System on Dairy Cow Fertility, Measured Using Progesterone Profiles and On-Farm Recording
}

\author{
G. E. Pollott' ${ }^{1,2}$ and M. P. Coffey \\ Sustainable Livestock Systems Group, Scottish Agricultural College, Bush Estate, Penicuik, Midlothian, EH26 OPH, United Kingdom
}

\begin{abstract}
The recent decline in dairy cow fertility appears to be a feature of several countries and is often linked to increased milk production, but its causes are not always obvious. A fully recorded 200-cow dairy herd, split into 2 genetic lines maintained on 2 production systems, was used to investigate the relationship between several measures of fertility, production, and energy balance. The 2 genetic lines were composed of a selection line, derived from the highest genetic merit bulls available, and a control line, maintained at the average of UK genetic merit at the time of mating. The production systems were a high-concentrate and a high-forage system. Thrice-weekly milk progesterone samples allowed an objective measurement of luteal cycling activity, and farm observations of estrus, services, and calving provided data on various measures of fertility. Energy balance in early lactation was calculated from daily live weight and weekly BCS measurements. Control line cows commenced luteal activity (C-LA) $6 \mathrm{~d}$ before selection line cows, had their first heat $14 \mathrm{~d}$ earlier, and had longer gestation periods by $3.7 \mathrm{~d}$. They also had a lower incidence of silent heats. Cows on the high-forage system commenced luteal activity $6 \mathrm{~d}$ before those on the high-concentrate system, had longer gestation intervals by $3.9 \mathrm{~d}$, held to first service better, had longer luteal phases and shorter interluteal periods in their estrus cycles. Characteristics of energy balance were used to see if they could account for the fertility differences between both genetic lines and systems. The commencement of luteal activity and day of first heat were analyzed using a REML mixed model approach. Mean energy content and mean energy balance over the first $25 \mathrm{~d}$ of lactation had an effect on C-LA and accounted for the differences found between production systems but not genetic lines. Day of energy balance nadir, mean energy content in the first $25 \mathrm{~d}$, and C-LA
\end{abstract}

Received December 4, 2007.

Accepted May 21, 2008.

${ }^{1}$ Present address: Royal Veterinary College, Royal College Street, London, NW1 0TU, UK.

${ }^{2}$ Corresponding author: gpollott@rvc.ac.uk affected day of first heat, but the differences between genetic lines were still apparent. These results suggest a link between high performance and reduced dairy cow fertility; high performance originating from different feeding systems was largely due to differences in energy balance, whereas those originating from genetics remained when energy balance characteristics were taken into account. This suggests a real genetic change in fertility due to selection for high genetic merit.

Key words: genetic, energy balance, fertility, progesterone

\section{INTRODUCTION}

The decline in fertility in dairy herds, both at the phenotypic and genetic level, appears to be a feature of dairy industries in many countries (e.g., Butler and Smith, 1989; Royal et al., 2000; and A.-Ranberg et al., 2003). Most of these studies have used time trends from national or regional dairy cow recording schemes to describe the growing problem. However, the type of animals used in such analyses may have also changed over time, as have the production methods, herd sizes, and genetic makeup of the animals. This backdrop of change makes it somewhat difficult to ascribe the decline in fertility to specific causes. When using commercial farm records in such studies, it is often hard to determine the influence of management system on production, health, and functional traits because system is usually confounded with farm (management level, health status, climate, housing environment, husbandry, etc.) and genetics. Many of the measures of fertility used in these studies rely on farm observation, which may not always reflect the real underlying physiological state of the animal. The traditional measurement of fertility on farms serves a useful purpose but is vulnerable to missing key events through silent heats and poor observation. Progesterone profiling provides a more objective method for tracking reproductive events in dairy cows (Lamming and Bulman, 1976) and is being developed for on-farm use. Another key question often discussed in relation to declining fertility is the role of increasing milk yield compared with that of energy balance (Butler and Smith, 1989). 
The national breeding schemes referred to above are not easily able to collect energy balance data for the animals in question.

The Langhill herd maintained by the Scottish Agricultural College at its Crichton Royal Farm (CRF) provides the opportunity to study the effects of both system and genetics on dairy traits because it is composed of 2 different levels of genetic merit with 2 contrasting systems of management. This herd is monitored for feed intake, condition scored, and weighed regularly, and feeds are sampled and analyzed routinely. In addition, milk progesterone profiles have been monitored in this herd and thus provide a more objective view of a cow's reproductive physiology than do simple visible displays of estrus. This paper reports the results of a study that used both progesterone profiles and energy balance in early lactation to investigate differences in dairy cow fertility due to production system and genetic merit.

\section{MATERIALS AND METHODS}

The data used in this study were collected from cows on the Scottish Agricultural College's Dairy Research Centre at CRF, Dumfries, Scotland $\left(55^{\circ} 02^{\prime} \mathrm{N}, 3^{\circ} 34^{\prime}\right.$ $\mathrm{W} ; \sim 40 \mathrm{~m}$ above sea level). The cows had previously made up the Langhill herd, Edinburgh (Veerkamp et al., 1995; Langhill, 1999; Pryce et al., 1999) and were transferred to CRF in September 2001. The herd was part of a long-term breeding experiment comparing 2 genetic lines on 2 systems of production. The herd was maintained at approximately 200 milking cows divided evenly between 4 groups made up from every combination of the genetic lines and production systems. Cows reaching their fifth lactation were removed from the herd, transferred into a commercial herd, and replaced by heifers. Thus, over the 2 -yr period covered by this study, the total number of cows recorded in the herd was greater than 200 due to the normal replacement policy of the herd.

\section{Genetic Lines}

The 2 genetic lines were designated as control and selection lines. Cows were allocated to the same line as their dams and remained there throughout their productive life. Cow sires in the selection line were picked on the basis of their genetic merit for fat and protein PTA, available sires with the highest fat+protein $\mathrm{kg}$ of PTA being chosen at the time of AI. Sires of control line cows were selected to have the average genetic merit for fat+protein $\mathrm{kg}$ of UK animals at the time of AI. In both lines, matings were arranged such that the inbreeding coefficient was $<6 \%$ at all matings. Cows from both lines were randomly allocated to production system groups to maintain balanced groups of cows. Cows were kept together and treated the same at all times, except where the production systems required management differences.

\section{Production System Groups}

Cows at CRF were randomly allocated to a highconcentrate or a high-forage production system at first calving in such a way as to keep the groups balanced for numbers. The high-forage system relied on homegrown feeds, including maize and other wholecrop cereals, and the cows were grazed on grass during the summer months. The winter ration consisted of grass silage, maize silage, and alkalage, at a ratio of 60:20:20 on a DM basis, plus a protein supplement. The ration was fed as a TMR. At least $75 \%$ of the DM of the ration was designed to come from forages. The target $\mathrm{ME}$ content was $11.5 \mathrm{MJ} / \mathrm{kg}$ of DM with a target CP content of 180 $\mathrm{g} / \mathrm{kg}$ of DM. Forages were supplemented with a range of energy and protein sources to meet these targets.

The high-concentrate system cows were housed all year, with access to an exercise area during the summer months. Their ration also contained the forages mentioned above, in the same DM ratio to each other, with a supplement blend of energy and protein ingredients. The target ration ME content was $12.3 \mathrm{MJ} / \mathrm{kg}$ of $\mathrm{DM}$ with a target CP content of $185 \mathrm{~g} / \mathrm{kg}$ of DM.

\section{Breeding Policy}

The breeding policy at CRF was designed to allow cows the maximum opportunity to express their fertility characteristics within recommended welfare guidelines. Heifers were initially mated at about 13 mo of age, depending on their live weight, to calve for the first time as close as possible to 24 mo of age. After calving, cows were bred at the first observed heat on or after $d$ 42 of lactation. In all, a cow was permitted 7 services in a given breeding period before being removed from the herd. Cows failing to show heat after d 42 of lactation were treated by the veterinarian as appropriate for normal farm practice. No cow was artificially treated to induce estrus.

\section{Traits and Recording}

Traits Determined from the Milk Progesterone Profiles. Fertility in dairy cows is commonly measured as a series of time-related events, or intervals between them, or both. However, the use of milk progesterone profiles allows an insight into one set of key underlying mechanisms. Milk samples were taken on Mondays, Wednesdays, and Fridays each week from cows in the 
herd calving from September 2003 to August 2005, during the first $140 \mathrm{~d}$ of the subsequent lactation. Milk progesterone analysis was carried out on whole milk by ELISA (Ridgeway Scientific, Alvington, UK) with a reading range of 1 to $15 \mathrm{ng} / \mathrm{mL}$ and milk progesterone levels recorded $(\mathrm{ng} / \mathrm{mL})$. Measurements below the lowest $1 \mathrm{ng} / \mathrm{mL}$ standard, which thus did not give a reading, were recorded as $0.1 \mathrm{ng} / \mathrm{mL}$. The intra- and interassay coefficients of variation were 6 and 13\%, respectively, and were worked out using quality control samples. At least 2 consecutive readings of $\geq 3 \mathrm{ng} / \mathrm{mL}$ were taken as evidence of luteal activity. A typical normal progesterone profile is illustrated in Figure 1. This cow first exceeded the threshold level of progesterone of $3 \mathrm{ng} / \mathrm{mL}$ (Lamming and Bulman, 1976) on d 35, had a cycle with no service, had another cycle starting on d 53 , was served, and had a positive pregnancy diagnosis on $\mathrm{d}$ 109. The following traits were calculated from the progesterone data using the methods outlined by Royal et al. (2000): interval from calving to first luteal activity (C-LA; d), average progesterone level (ng/mL), length of the luteal phase (d), interovulatory period (cycle length, d), and length of the interluteal period (d). In addition the number of cycles per lactation was counted.

The luteal cycle data were analyzed and various abnormalities noted. These abnormalities in cycle patterns were delayed ovulation for $>45 \mathrm{~d}$ postpartum (DOV1), prolonged interluteal interval and delayed ovulation where there was $>12$ d between 2 luteal phases (DOV2), delayed luteolysis during the first cycle with a persistent corpus luteum (PCL1), and delayed luteolysis during subsequent cycles with persistent corpus luteum (PCL2; Lamming and Darwash, 1998).

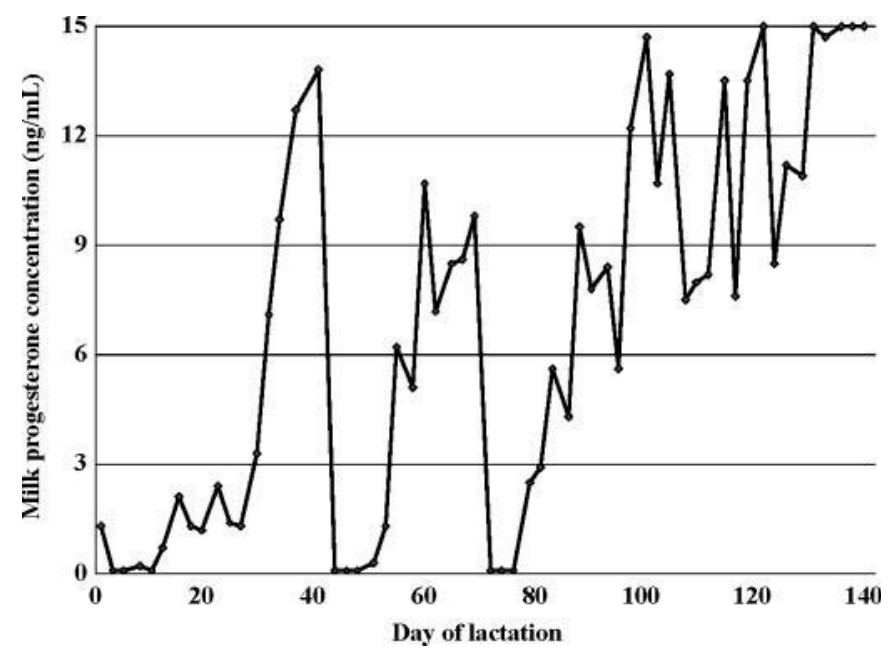

Figure 1. A typical progesterone profile showing 2 complete luteal cycles followed by pregnancy.
Traits Recorded by, or Calculated from, Farm Observation. Cows were milked 3 times per day and mostly fed and maintained indoors. In addition, $1 \mathrm{~h}$ per day was allocated for heat observation of the herd. This provided many opportunities for farm observation for signs of breeding activity and reduced the likelihood of missing signs of behavioral estrus. The days of heats, services, and calvings were recorded. This provided data from which to calculate the day of first observed heat (DFH), the day of first service, and in combination with subsequent calving information, the day of successful service. The number of heats and the number of services were counted from the data. Gestation length was calculated from the difference between the day of successful service and the next calving date, but any aborted calves were excluded from the data set. Calving interval was calculated from the dates of 2 consecutive calvings, again excluding any aborted calvings. All other interval traits were calculated from the above traits. Because of the breeding policy at $\mathrm{CRF}$ requiring first service to occur at the first heat on or after d 42 of lactation, several traits were recalculated from this starting point (see Tables 1 and 2). One additional trait, the incidence of silent heats, was calculated by combining the farm and cycle data. In this case, a silent heat was assumed to have occurred when a cycle, identified from the progesterone profiles, was not preceded by an observed heat. A silent heat was given a value of 1 and an observed heat the value 0 and the trait analyzed as a binary trait.

\section{Statistical Analyses and Models}

The data collected in this study can be divided into 3 groups of traits: those measured once per lactation, those measured on each luteal cycle, and traits describing the incidence of a particular cycle abnormality. The statistical analyses will be described by these trait groups.

Traits Measured Once per Lactation. Tables 1 and 2 show 19 traits measured once per lactation. These were composed of basic descriptions of fertility (e.g., day of first heat), intervals between 2 fertility events (e.g., interval from first heat to first service), and traits relating to events post $42 \mathrm{nd}$ day of lactation. This latter group was analyzed because one of the management practices at CRF was to delay first service until the first heat on or after the 42nd day of lactation; this practice created a bias in some traits where animals were held back from naturally expressing their full potential for fertility.

The majority of these traits had skewed distributions and so they were transformed before analysis. Transformation was carried out by taking either the natural 
Table 1. Basic statistics of 11 fertility traits measured on a lactation basis

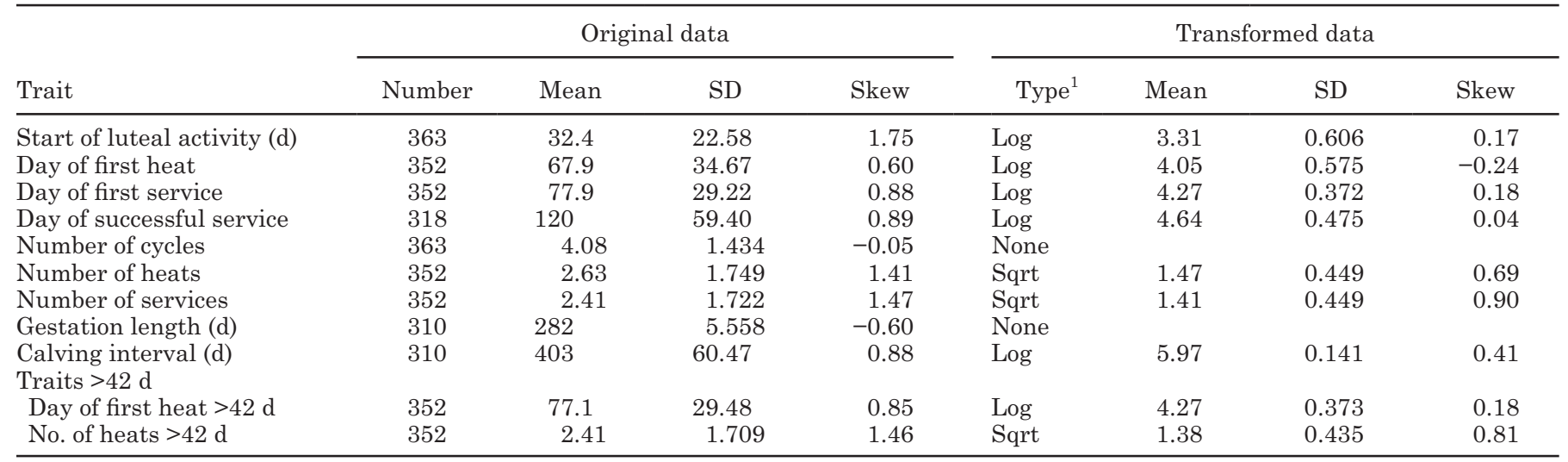

${ }^{1}$ Type of transformation: Log = natural logarithm; Sqrt $=$ square root.

logarithm or square root of the trait, as determined by its distribution after transformation. In addition, 5 of the interval traits were also converted into binary traits. For example, the interval from first heat to successful service was coded as 0 if service occurred within $1 \mathrm{~d}$ of first heat and as 1 if it was greater than $1 \mathrm{~d}$. This recoding to a binary trait (values 0 or 1 ) was carried out for intervals from first heat to first AI, first heat to successful service, first service to successful service, first heat $>42 \mathrm{~d}$ to first AI, and first heat $>42 \mathrm{~d}$ to successful service. In each case, the value 0 was assigned to intervals of less than $1 \mathrm{~d}$. The use of transformations and binary trait analyses are shown in the results tables, as appropriate.

All traits shown in Tables 1 and 2 were analyzed by REML mixed model analyses in SAS (2004). The binary transformations of the traits were analyzed using ASREML (Gilmour et al., 2002) with a logittransformation applied to the binary data. The effects of genetic line, production system, lactation number, and year and month of calving were all fitted as fixed effects. The effect of cow within genetic line/production system group was fitted as a random effect. All firstorder interactions between the fixed effects were also fitted in the model. The model used was

$$
\begin{aligned}
\mathrm{y}_{\mathrm{ijklmno}} & =\mu+\mathrm{G}_{\mathrm{i}}+\mathrm{S}_{\mathrm{j}}+\mathrm{L}_{\mathrm{k}}+\mathrm{Y}_{\mathrm{l}}+\mathrm{M}_{\mathrm{m}}+\mathrm{A}_{\mathrm{n}(\mathrm{ij})} \\
& +[\text { Interactions }]+\mathrm{e}_{\mathrm{ijk} k m n o},
\end{aligned}
$$

where $\mu$ was the overall mean, $\mathrm{G}_{\mathrm{i}}$ was the effect of the ith genetic line ( $i=$ control or selection line), $S_{j}$ was the effect of the $j$ th production system $(j=$ high-forage or high-concentrate system), $L_{k}$ was the effect of the kth lactation number ( $k=1$ to 5), $\mathrm{Y}_{1}$ was the effect of the lth year of calving $(l=2003,2004$ or 2005$), M_{m}$ was the effect of the mth month of calving ( $m=1$ to 12$), A_{n(i j)}$ was the effect of the nth cow ( $n=1$ to 229$)$, and $e_{i j k l m n o}$ was the residual variance term associated with the o lactations ( $\mathrm{o}=1$ to 363 ). The index values of the effects shown in model 1 were for C-LA, but some effects had fewer levels in some analyses where less records were available (see Tables 1 and 2).

Table 2. Basic statistics of 8 fertility interval traits measured on a lactation basis (d)

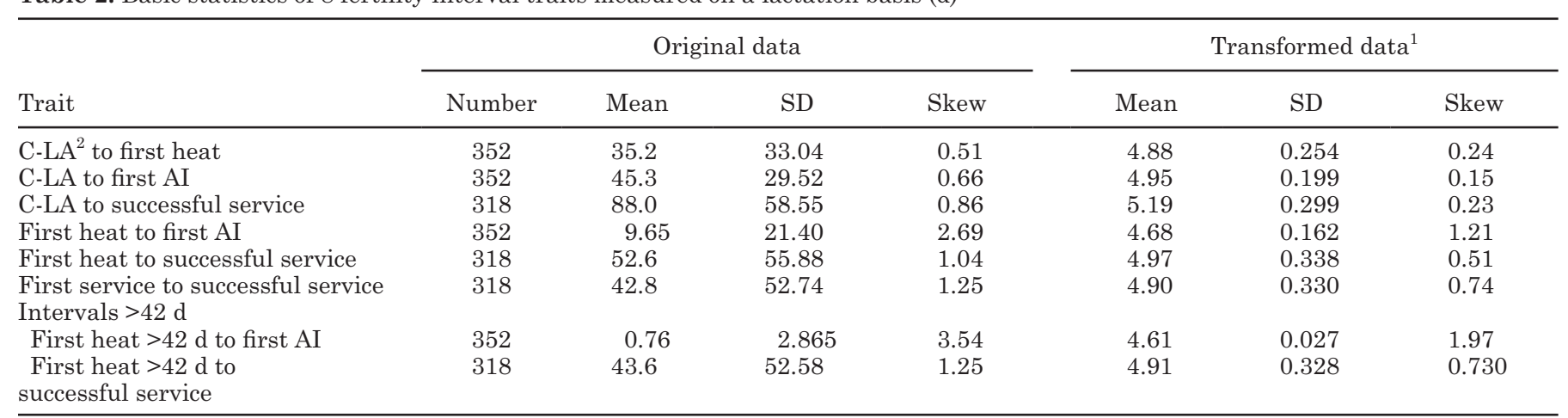

${ }^{1}$ All traits transformed using natural logarithms.

${ }^{2} \mathrm{C}-\mathrm{LA}=$ day in lactation of the commencement of luteal activity. 
The model was fitted using a step-down approach until only significant main effects remained in the model or main effects that were involved in a significant interaction. Results from the analysis were reported and effects considered to be significant when tested against the residual term using an $F$-test. The significance of the random cow effects was determined by carrying out a log-likelihood test on the likelihoods derived from 2 models, the full final model with and without the cow within genetic line/production system term included. The difference in likelihoods was tested against the chisquared distribution with $1 \mathrm{df}$. Least squares means were computed from the full final model and converted back to real values where transformations had been used.

Traits Measured Once per Cycle. Five traits that were characteristics of individual luteal cycles are shown in Table 3 . These traits were also $\log _{n}$ transformed as appropriate. A similar method was used for analyzing the cycle traits as described above for the lactation traits with the addition of cycle number as a fixed effect. Also, month in these analyses referred to the month in which the cycle started. In this case, the model was

$$
\begin{aligned}
\mathrm{y}_{\mathrm{ijklmnop}}= & \mu+\mathrm{G}_{\mathrm{i}}+\mathrm{S}_{\mathrm{j}}+\mathrm{L}_{\mathrm{k}}+\mathrm{Y}_{1}+\mathrm{M}_{\mathrm{m}}+\mathrm{C}_{\mathrm{p}}+\mathrm{A}_{\mathrm{n}(\mathrm{ij})} \\
& +[\text { Interactions }]+\mathrm{e}_{\mathrm{ijklmnop}}
\end{aligned}
$$

and the terms were as described above with the addition of $\mathrm{C}_{\mathrm{p}}$, the pth cycle number $(\mathrm{p}=1$ to 6$)$. In addition, the analysis of the incidence of silent heats included cycle length, mean progesterone level during the cycle, and days in milk as covariates.

Incidence of Cycle Abnormalities. The incidence of the 4 cycle abnormalities were analyzed using a chi-squared test to see if there was any influence of genetic line or production system. The occurrence of an abnormality during a lactation was coded as 1 and a 2 -way table of occurrence and group constructed. The table was tested against the chi-squared distribution with $1 \mathrm{df}$.

\section{Energy Balance}

Fertility is highly influenced by energy balance in early lactation (Butler and Smith, 1989; Beam and Butler, 1999; de Vries and Veerkamp, 2000). The 4 subgroups in this trial were characterized by large differences in milk yield and nutrient intake, and so the energy balance of the 4 groups would be expected to vary by design. To see if any fertility differences between groups could be explained by energy balance differences, the energy balance of each animal over the lactation was calculated from their daily live weight measurements and weekly BCS using the energy balance (EB2) methodology of Coffey et al. (2001). A typical energy content and energy balance profile is shown in Figure 2. Several traits were calculated from the energy balance curve; day of return to positive energy balance, day of energy balance nadir, level of energy balance nadir, mean energy content of the animal over the first $25 \mathrm{~d}$ of lactation and the mean energy balance over the first $25 \mathrm{~d}$ of lactation. All these traits were added to model 1 as covariates and analyzed in a stepdown approach using REML mixed model methodology in SAS. The early lactation traits C-LA and DFH were analyzed with this augmented model 1.

\section{RESULTS}

Between September 2003 and August 2005, 363 lactations from 229 cows were recorded as having a full $140 \mathrm{~d}$ set of progesterone readings. These lactations were used as the basis for the calculations reported below.

\section{The Average Cow at CRF}

Trait summaries are shown in Tables 1, 2, and 3. The 363 recorded lactations were split between the 2 genetic lines, with 191 control and 172 selection line lactations, and the 2 production systems, with 177 high-concentrate and 186 high-forage lactations. The mean lactation number was 2.25 . Cows started cycling on d 32 of lactation and were observed to have their first heat on $d$ 67. First service occurred on $d 78$, and cows were successfully served by d 120 with a gestation length of $282 \mathrm{~d}$. Calving interval averaged $403 \mathrm{~d}$. These fertility results were achieved with 4.08 luteal cycles

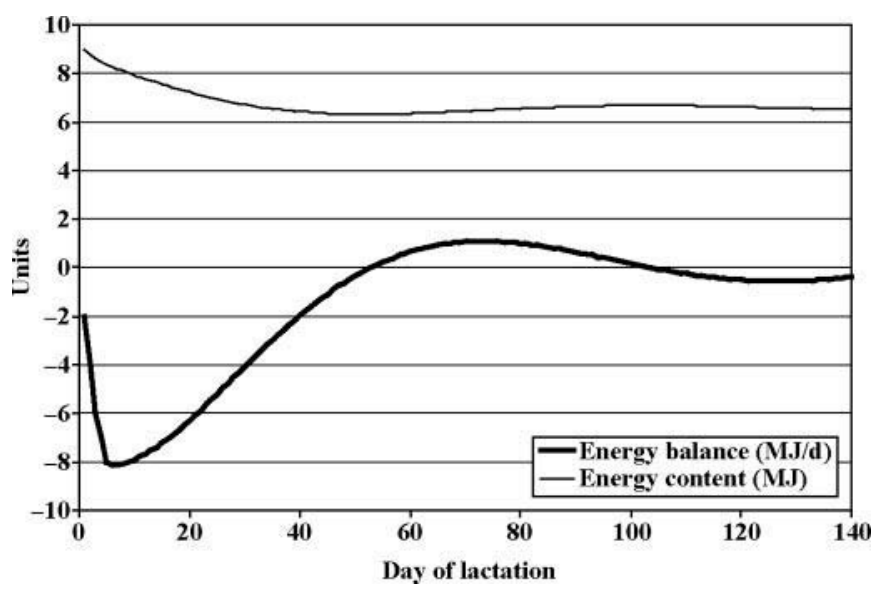

Figure 2. A typical energy content and energy balance profile. 
Table 3. Basic statistics of 5 luteal cycle traits

\begin{tabular}{|c|c|c|c|c|c|c|c|}
\hline Trait & \multicolumn{4}{|c|}{ Original data } & \multicolumn{3}{|c|}{ Transformed data ${ }^{1}$} \\
\hline Mean progesterone level (ng/mL) & 1,114 & 10.47 & 3.06 & -0.81 & & & \\
\hline Interovulatory period (d) & 1,114 & 22.4 & 9.22 & 1.79 & 3.04 & 0.388 & -0.16 \\
\hline Interluteal period $(\mathrm{d})$ & 1,114 & 7.57 & 5.94 & 4.57 & 1.85 & 0.550 & 0.39 \\
\hline Incidence of silent heats & 1,114 & 0.609 & 0.488 & -0.45 & & & \\
\hline
\end{tabular}

${ }^{1}$ All traits transformed using natural logarithms where shown; otherwise not required.

(including the one that resulted in pregnancy), 2.63 heats, and 2.41 services. Farm policy delayed the day of first service by about $10 \mathrm{~d}$ on average. The average luteal cycle lasted $22.4 \mathrm{~d}$ and was composed of a $14.7-\mathrm{d}$ luteal period and a 7.6-d interluteal period. About $61 \%$ of the completed luteal cycles were preceded by silent heats.

\section{Analysis of Variance and Least Squares Means Summaries}

A summary of the 11 analyses of variance derived from the fertility traits measured once per lactation is shown in Table 4. Six of the traits were $\log _{\mathrm{n}}$ transformed, 3 were square-root transformed, and 2 were normally distributed. Five traits were unaffected by any of the effects fitted in the model: day of successful service, number of heats, number of services, calving interval, and number of heats occurring after $\mathrm{d} 42$. In addition, 2 traits were only affected by the different cows used: day of first service and day of first heat after $\mathrm{d} 42$. The calving to first luteal activity interval was affected by all effects except cow. Month of calving and lactation number only affected the calving to first luteal activity interval and no other traits.
Differences between the genetic lines were found for the commencement of luteal activity, day of first heat, the number of cycles, and gestation length. The leastsquares means in Table 7 show that control line cows commenced luteal activity on d 25 of lactation, some $5 \mathrm{~d}$ earlier than selection line cows; control line cows had their first heat on d 53, compared with d 67 for the selection line, and had more cycles, 4.32 compared with 3.99 for the selection line. Control line cows had longer gestation intervals than selection line cows, $283.6 \mathrm{~d}$ compared with $280.9 \mathrm{~d}$.

Production system differences were found for the commencement of luteal activity, the number of cycles, and gestation length. High-forage cows started cycling $6 \mathrm{~d}$ before high-concentrate cows and had about 0.4 more cycles and a longer gestation length by $4 \mathrm{~d}$.

An ANOVA summary for the 8 interval traits is shown in Table 5. Lactation number did not affect any trait, and the effect of differences between cows was only found for the interval from C-LA to first heat $(P<$ 0.05). Differences between the genetic groups was apparent for the intervals first heat to first AI $\left(\log _{n}\right.$ and binary analyses), first heat to successful service ( $\log _{n}$ and binary), and first heat after d 42 to first AI ( $\left.\log _{n}\right)$. The least squares means in Table 7 show that control

Table 4. An ANOVA summary of 11 fertility traits measured on a lactation basis

\begin{tabular}{|c|c|c|c|c|c|c|c|c|}
\hline Trait & Trans $^{1}$ & $\mathrm{RMS}^{2}$ & Cow & Genetic group & System & Lactation no. & Year & Month \\
\hline Day of first heat & $\log$ & 0.227 & $*$ & $* *$ & NS & $\mathrm{NS}$ & $* *$ & NS \\
\hline Day of first service & Log & 0.0928 & * & NS & NS & NS & NS & NS \\
\hline Number of cycles & & 2.02 & NS & $*$ & $*$ & NS & NS & NS \\
\hline Number of heats & Sqrt & 0.210 & NS & NS & NS & NS & NS & NS \\
\hline Number of services & Sqrt & 0.225 & NS & NS & NS & NS & NS & NS \\
\hline \multicolumn{9}{|l|}{ Traits $>42$} \\
\hline Day of first heat $>42 \mathrm{~d}$ & Log & 0.0166 & * & NS & NS & NS & NS & NS \\
\hline No. of heats $>42 \mathrm{~d}$ & Sqrt & 0.227 & NS & NS & NS & NS & NS & NS \\
\hline
\end{tabular}

${ }^{1}$ Type of transformation: Log = natural logarithm; Sqrt $=$ square root.

${ }^{2} \mathrm{RMS}=$ residual mean square.

${ }^{3} \mathrm{C}$-LA $=$ interval from calving to the start of luteal activity.

${ }^{*} P<0.05,{ }^{* *} P<0.01,{ }^{* * *} P<0.001$. 
Table 5. ANOVA summary of 8 fertility interval traits measured on a lactation basis $(d)^{1}$

\begin{tabular}{|c|c|c|c|c|c|c|c|}
\hline Trait & Trans $^{2}$ & $\mathrm{RMS}^{3}$ & $\begin{array}{l}\text { Genetic } \\
\text { group }\end{array}$ & System & Lactation no. & Year & Month \\
\hline C-LA ${ }^{4}$ to first heat & $\log$ & 0.0437 & NS & NS & NS & $* * *$ & NS \\
\hline C-LA to first AI & Log & 0.0325 & NS & NS & NS & NS & $*$ \\
\hline First heat to first AI & Log & 0.0234 & $* *$ & NS & NS & $* * *$ & NS \\
\hline First heat to successful service & Log & 0.0997 & $*$ & NS & NS & * & $*$ \\
\hline First service to successful service & Log & 0.0997 & NS & NS & NS & NS & NS \\
\hline \multicolumn{8}{|l|}{ Intervals $>42$} \\
\hline First heat $>42$ to first AI & Log & 0.000727 & * & NS & NS & NS & NS \\
\hline First heat $>42$ to successful service & Log & 0.0976 & NS & NS & NS & NS & NS \\
\hline First heat $>42$ to first AI & Bin & & NS & NS & NS & NS & NS \\
\hline First heat $>42$ to successful service & Bin & & NS & * & NS & NS & NS \\
\hline
\end{tabular}

${ }^{1}$ Cow effect not shown but it only had a significant effect on C-LA to first heat $(P<0.05)$.

${ }^{2}$ Type of transformation: $\log =$ natural logarithm; Bin = binary trait.

${ }^{3} \mathrm{RMS}=$ residual mean square; not available for binary traits.

${ }^{4} \mathrm{C}-\mathrm{LA}=$ interval from calving to the start of luteal activity.

${ }^{*} P<0.05,{ }^{* *} P<0.01,{ }^{* * *} P<0.001$.

line cows had longer intervals than selection line cows for first heat to first AI (about $6 \mathrm{~d}$ ), first heat to successful service (12.6 d), and first heat after d 42 to first AI (0.59 d). Control line cows also had lower conception rates than selection line cows, as shown by the binary analysis of first heat to first AI interval and first heat to successful service.

Differences between the 2 production systems were found for the intervals of first heat to successful service (binary) and first heat after d 42 to successful service (binary). Table 7 shows that the high-forage cows had lower conception rates than the high-concentrate cows.

Three of the 5 luteal cycle traits were $\log _{n}$ transformed (Table 6); only mean progesterone level was normally distributed. Month of calving affected 4 of the luteal cycle traits, whereas only silent heat was affected by genetic group. In this case the selection line had a greater incidence of silent heats than the control line by about $6 \%$.

Production system influenced the length of the luteal phase and the interluteal period. Table 7 shows that the high-forage cows had a longer luteal phase, by 0.9 $\mathrm{d}$, but had a shorter interluteal period $(0.8 \mathrm{~d})$; these effects cancelled each other out to leave the interovulatory period (cycle length) similar for both production systems. A higher incidence of silent heats was associated with lower mean progesterone levels and shorter cycle lengths, and shorter cycle lengths occurred earlier in the lactation.

\section{Incidence of Luteal Cycle Abnormalities}

The chi-squared analyses carried out on the incidence of luteal cycle abnormalities are summarized in Table 8. There were significant differences between the genetic lines and production systems in the incidence of delayed ovulation postpartum (DOV1). The selection line and the high-concentrate system had greater than expected incidence. No difference in the incidence of subsequent delayed ovulations (DOV2) was observed between the genetic lines, but high-concentrate cows had a greater incidence of delayed ovulation between cycles than high-forage cows. No effect of genetic line or

Table 6. ANOVA summary of 5 luteal cycle traits ${ }^{1}$

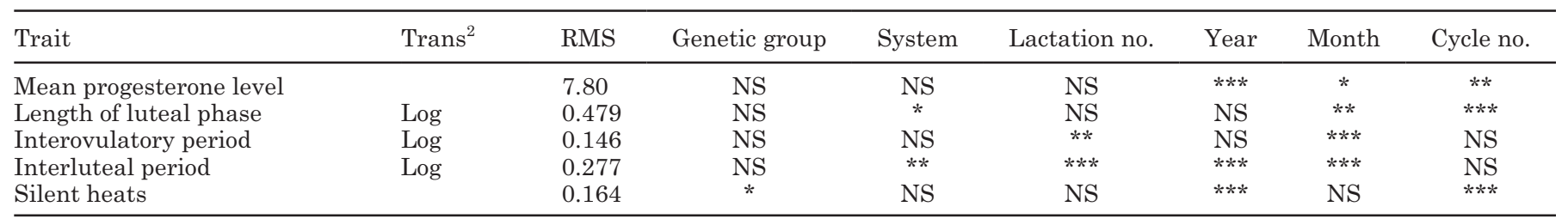

${ }^{1}$ Cow effect not shown, but it only had a significant effect on mean progesterone level $(*)$ and silent heat $(*)$; silent heats related to covariates cycle length ( $\operatorname{sign}$ of covariance $-;{ }^{* *}$ ), days in milk $(-; *)$, and mean progesterone level of cycle $(-; * * *)$.

${ }^{2}$ Type of transformation: $\log =$ natural logarithm.

${ }^{*} P<0.05,{ }^{* *} P<0.01,{ }^{* * *} P<0.001$. 
Table 7. Least squares means of traits in which genetic line and production system were found to contain significant differences $(P<0.05)$

\begin{tabular}{|c|c|c|c|c|}
\hline Trait & Control & Selection & High concentration & High forage \\
\hline Day of commencement of luteal activity & 25.7 & 30.9 & 31.2 & 25.3 \\
\hline Day of first heat & 53.7 & 67.2 & NS & NS \\
\hline Number of cycles & 4.32 & 3.99 & 3.98 & 4.33 \\
\hline \multicolumn{5}{|l|}{ Intervals (d) } \\
\hline First heat to first AI & 11.7 & 5.9 & NS & NS \\
\hline First heat to successful service & 61.8 & 49.2 & NS & NS \\
\hline First heat to first AI (binary) & 0.301 & 0.157 & NS & NS \\
\hline First heat $>42$ to successful service (binary) & NS & NS & 0.540 & 0.706 \\
\hline \multicolumn{5}{|l|}{ Cycle data } \\
\hline Length of luteal phase $(d)$ & NS & NS & 12.3 & 13.2 \\
\hline Interluteal period $(\mathrm{d})$ & NS & NS & 9.5 & 8.7 \\
\hline Silent heats (incidence) & 0.65 & 0.71 & NS & NS \\
\hline
\end{tabular}

production system was observed on persistent corpora lutea in the first cycle (PCL1). Persistent corpora lutea in subsequent cycles (PCL2) were a feature of control line cows.

\section{Energy Balance}

The results of fitting energy balance profile characteristics (Table 9) to model 1 for the day of commencement of luteal activity and day of first heat are summarized in Table 10. The commencement of luteal activity was influenced by the mean energy content of the cow over the first $25 \mathrm{~d}$ of lactation and the mean energy balance in the same period. Comparing this analysis with the results in the first row of Table 4 indicates that the differences in production system, lactation number, and month of calving found in Table 4 could be explained by the energy balance characteristics added to the model.
On the other hand, the differences between genetic lines and year remained significant. By using the same logic applied to day of first heat, as shown in Tables 4 and 9 , the differences in genetic line and year of calving were found to be significant in both analyses. Thus these effects were also independent of the energy balance characteristics fitted and also C-LA.

\section{DISCUSSION}

\section{Genetic Line}

Genetic studies of national recording scheme data suggest that dairy cow fertility is under genetic control but that the influence of genetics, compared with all other so-called environmental effects, is low. For example, Wall et al. (2003) reported that the heritabilities of calving interval, days to first service, nonreturn rate,

Table 8. Incidence of luteal cycle abnormalities by genetic line and production system and their analysis using a chi-squared test ${ }^{1}$

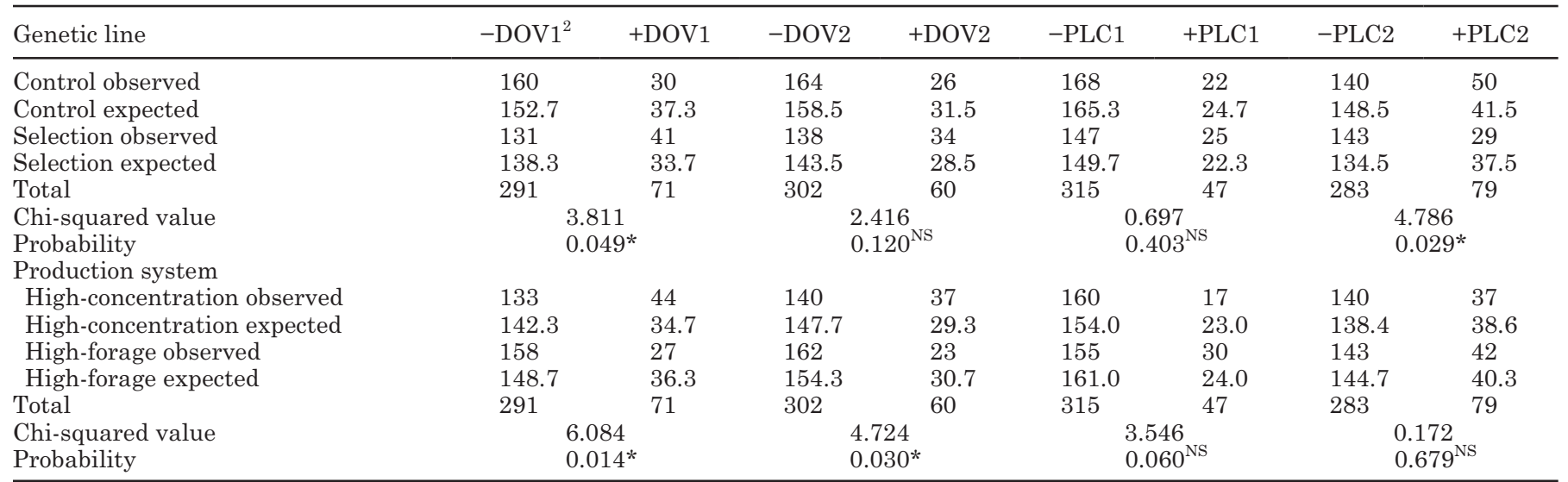

${ }^{1}$ DOV1 = delayed ovulation for $>45$ d postpartum; DOV2 = delayed ovulation with $>12 \mathrm{~d}$ between 2 luteal phases; PLC1 = delayed luteolysis during first cycle with persistent corpus luteum; PLC2 = delayed luteolysis during subsequent cycles with persistent corpus luteum.

${ }^{2}$ Plus/minus (+/-) indicates a cycle with or without the stated abnormality.

${ }^{*} P<0.05$. 
Table 9. Statistics of traits used as explanatory variables in the analyses or as part of energy balance calculations

\begin{tabular}{lcc}
\hline Trait & Mean & SD \\
\hline Milk yield (305-d; kg) & 8,465 & 2,142 \\
Fat yield (305-d; kg) & 309 & 76.5 \\
Protein yield (305-d; kg) & 272 & 67.8 \\
Days in milk & 286 & 40.5 \\
Live weight (kg) & 641 & 66.5 \\
BCS (0 to 5 scale) & 2.24 & 0.330 \\
Energy content (mean of first 25 d; MJ) & 5,397 & 854.5 \\
Day of return to positive energy balance & 52.9 & 35.31 \\
Day of energy balance nadir & 79.0 & 46.24 \\
Level of energy balance nadir (MJ/d) & -6.90 & 12.08 \\
Energy balance (mean of first 25 d; MJ/d) & -11.5 & 59.64 \\
Calf birth weight (kg) & 45.8 & 5.78 \\
\hline
\end{tabular}

and the number of inseminations per conception were $0.033 \pm 0.001,0.035 \pm 0.001,0.018 \pm 0.001$, and 0.020 \pm 0.002 , respectively. This level of genetic control has been reflected in several other farm or regional studies including Pryce et al. (1999) and Royal et al. (2002). An alternative way to look at the effect of genetics on fertility may be to look at comparative breed performance, although the number of studies using 2 or more breeds on the same farm at the same time is very limited. Wicks et al. (2004) compared Holstein-Friesian and Norwegian Red cows and found that Norwegian Reds had a day of first service $16.9 \mathrm{~d}$ earlier than the Holstein Friesians. Using the same animals, Crawford et al. (2001) suggested an advantage in the commencement of luteal activity to Norwegian Reds of about $10 \mathrm{~d}$ on a high-concentrate diet. Horan et al. (2004) compared 3 strains of Holstein-Friesian bulls (high-production North American, and high-durability North American and New Zealand), all mated to Holstein-Friesian cows from the same herd. Differences between strains for fertility characteristics were found for gestation length,

Table 10. The results of fitting energy balance (EB) characteristics to the model for the commencement of luteal activity (C-LA) and day of first heat (DFH) ${ }^{1}$

\begin{tabular}{lcc}
\hline Effect & C-LA & DFH \\
\hline Genetic line & $*$ & $*$ \\
Production system & NS & NS \\
Lactation number & NS & NS \\
Year & $*$ & $* * *$ \\
Month of calving & NS & NS \\
Progesterone & NS & NS \\
Day of positive EB & NS & NS \\
Day of EB nadir & NS & $* *+$ \\
Level of EB nadir & NS & NS \\
Mean energy content first 25 d & $*-$ & $*-$ \\
Mean EB first 25 d & $*-$ & NS \\
C-LA & & $* * *+$ \\
\hline
\end{tabular}

${ }^{1}+$ or - indicates the sign of the regression coefficient.

${ }^{*} P<0.05 ;{ }^{* *} P<0.01 ; * * * P<0.001$. conception rate to first and second service, and overall pregnancy rate. For these traits, the high production group always had the lowest fertility and longest gestation length, whereas the New Zealand group had the greatest fertility.

Hageman et al. (1991) report the fertility results from a trial using high and average production lines of Holsteins. They found differences between the 2 lines in the interval between first heat and first service and gestation length in maiden heifers, and between days open and calving interval in second-parity cows. In addition, they demonstrated significant positive linear regression coefficients for the following traits with milk yield: days to first heat, days open, and calving interval. This set of results also indicates lower levels of fertility with increasing milk yield. The high-production line had the lowest fertility. Reporting on the Langhill herd, Pryce et al. (1999) found differences between a high and average production line for the incidence of silent heats, the rate of conception to first service, calving interval, day of first heat, day of first service, and days open; they also found that the high-production line had the lowest fertility for all traits.

Other evidence for a link between genetic level and fertility can be seen from the relationship between bull index for fertility and UK production index value shown in Figure 3. An increase in the production index of $£ 1$ was associated with a $£ 0.05$ reduction in the fertility index. The $\mathrm{R}^{2}$ of the relationship was small, however, indicating a wide range in fertility at any given production level. In addition, several authors have demonstrated both genetic and phenotypic correlations between production and fertility. For example, Wall et al. (2003) showed a range of unfavorable genetic correlations between 5 production traits and indexes with 4 fertility traits [calving interval, days to first service, nonreturn rate to $56 \mathrm{~d}$ (negative), and the number of inseminations per conception]. The genetic correlations ranged from 0.38 to 0.67 . 


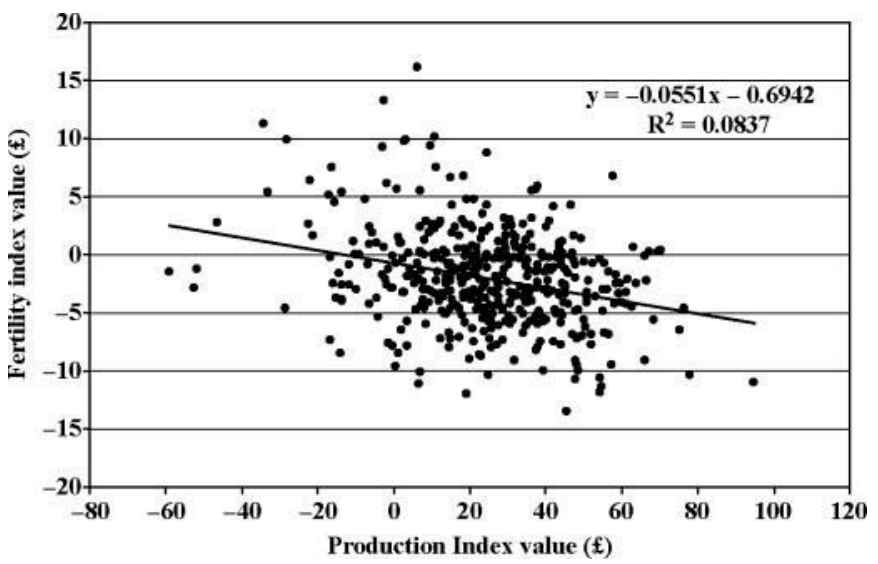

Figure 3. The relationship between United Kingdom bull index values for production and fertility.

Further evidence of a link between genetics and fertility comes from national studies of breed performance. Hare et al. (2006) reported changes in fertility between 1980 and 1998 for 5 US dairy breeds. The range of breed differences in calving interval was about $20 \mathrm{~d}$, and all breeds showed a decline in fertility of about $1 \mathrm{~d}$ per year over the period studied.

The evidence reviewed above suggests a link between genetics and fertility in dairy cows, but several authors have highlighted the negative effect of low energy balance on fertility (Butler and Smith, 1989; Beam and Butler, 1999; de Vries and Veerkamp, 2000), and several components of energy balance are highly influenced by genetics. In the context of this study, high levels of milk production are associated with energy deficit in early lactation, which, in turn, is linked to lower levels of fertility. Thus, the relationship between genetics and fertility could be completely mediated through milk production level.

One key question addressed by the research reported here relates to whether the way in which the 2 genetic lines were formed at CRF has resulted in differences in fertility, and if so, what was the nature of this difference. Control line cows commenced luteal activity on $\mathrm{d} 25$ of lactation, $5 \mathrm{~d}$ before selection line cows, and had their first observed heat on d 53, $14 \mathrm{~d}$ earlier than the selection line. This result was corroborated by the greater than expected incidence of delayed ovulation postpartum found in the luteal cycle abnormalities analysis for the selection line. Several authors have suggested that energy balance in early lactation influences the onset of cycling activity (e.g., de Vries and Veerkamp, 2000). After fitting several characteristics of early lactation energy balance to both C-LA and day of first heat in the present study, a difference was still present between the 2 lines of $5 \mathrm{~d}$ for C-LA and $10 \mathrm{~d}$ for day of first heat. This result suggests that there has been a change in the genes directly affecting fertility rather than just those affecting fertility via energy balance, milk yield, feed intake, and body fat changes indirectly.

An alternative way to look at these results may be in terms of the breed composition of the 2 lines. The current UK Holstein population is largely the result of grading up from British Friesian animals using imported Holstein semen (Simm, 1998). The breed makeup of the 2 lines may be one cause for the differences found in fertility. The mean proportion of Holstein genes in the cows used in this study was $95.7 \%$ for the control line and $96.9 \%$ for the selection line. This $1.2 \%$ is a very small difference and seems unlikely to be a major cause of differences between the 2 lines in fertility, although this difference tells us nothing about the actual genes and polymorphisms occurring in the 2 groups. Wall et al. (2005) estimated the difference between $0 \%$ (Friesian) and 100\% Holstein animals as being $12.2 \mathrm{~d}$ for calving interval and $3.95 \mathrm{~d}$ for days to first service. Assuming a linear trend over the range of Holstein percentages of cows, a $1 \%$ difference would equate to $0.12 \mathrm{~d}$ in calving interval and $0.0395 \mathrm{~d}$ in days to first service, which does not explain the differences found here.

The farm at CRF has a policy of delaying first service until the first heat on or after d 42 of lactation. This policy had a greater effect on the control line than the selection line because more control line cows had their first heat before d 42 of lactation (34 vs. $15 \%$ for the selection line). The net result was a loss of $6.7 \mathrm{~d}$ in potential days to first service in the control line compared with the selection line. Thus, significant differences between the 2 lines in the number of cycles, interval from first heat to first AI, and interval from first heat to successful service were all due to this artificial constraint. However, the interval from first heat post d 42 to first AI was about $0.6 \mathrm{~d}$ shorter for selection line cows.

The genetic differences in gestation length were investigated by adding sex and birth weight to the model. When analyzed together, birth weight had a significant relationship with gestation length, but the genetic differences remained and there was no effect of sex. If sex was added to the model without birth weight, then there was a difference in gestation length between the sexes. Thus, the effect of sex on gestation length can be explained by differences in the mean weight of the sexes, but neither birth weight nor sex accounted for the differences between the 2 genetic lines.

Four of the 5 luteal cycle traits were totally unaffected by genetic line, and so these characteristics of reproduction appear to be invariant to large changes in production characteristics brought about by differing 
genotypes. However, there were differences between the 2 lines in the incidence of cycle abnormalities and the occurrence of silent heats. As noted above, there were differences in the incidence of delayed ovulation postpartum, and in addition, the control line cows had a higher than expected incidence of type 2 persistent corpora lutea (PCL2). The occurrence of these abnormalities results in longer intervals to observed heat and successful service, thus reducing fertility.

\section{Production System}

Energy balance is often quoted as having a key influence on fertility (Beam and Butler, 1999; Westwood et al., 2002). In early lactation, milk production and feed/ energy intake are changing rapidly thus the energy balance may change rapidly too. The BCS is often quoted as an indicator of energy balance, but many CRF cows were still growing in their first and second lactation and so live weight needs to be considered as well. Thus the EB2 calculation of Coffey et al. (2001) was used to indicate energy status and model the changes in energy balance over the lactation.

Zurek et al. (1995) estimated that the number of days to the postpartum nadir of energy balance was related to C-LA such that cows resumed ovulation $15.4 \pm 1.2$ $\mathrm{d}$ after the nadir of energy balance. Butler and Smith (1989) suggested that the resumption of ovulation was related to the average energy balance during the first $20 \mathrm{~d}$ of lactation. There is thus a demonstrable link between energy dynamics and the resumption of fertility postpartum. However, Diskin et al. (2003) suggest that it is the return to positive energy balance that triggers ovulation.

Cows on the high-forage diet commenced luteal activity $6 \mathrm{~d}$ earlier than those on the high-concentrate diet, but there was no difference in the days to first heat between the 2 systems. This result was reflected in the luteal cycle abnormality analysis, which showed a higher than expected incidence of delayed ovulation postpartum for the high-concentrate cows. The differences between the 2 production systems for C-LA disappeared when characteristics of early-lactation energy balance were fitted in the model. This implies that the production system differences in C-LA were due to the effects of the 2 nutritional regimens through characteristics such as day of energy balance nadir, mean energy content, and mean energy balance over the first $25 \mathrm{~d}$ of lactation. The proportion of the 2 groups having their first heat before d 42 was similar ( 23 vs. $27 \%$ for high-concentrate and high-forage groups, respectively), and the mean loss of days to first service because of the farm service policy was 9.2 and $10.0 \mathrm{~d}$, respectively.
The reproductive performance of the high-forage group was poorer than that of the high-concentrate group. The high-forage group required more luteal cycles to become pregnant and had poorer conception characteristics than the high-concentrate animals.

When birth weight and sex were added to the model analyzing gestation length, the difference between the production systems was still highly significant. Thus, as with the genetic lines, these 2 additional factors did not account for the difference in gestation length between the 2 systems, and so some other effect, or effects, must be causing this difference.

In contrast to the genetic line results, production system did have an effect on luteal cycle characteristics. High-forage cows had longer luteal phases in their cycles, by $0.9 \mathrm{~d}$, but had shorter interluteal intervals, by $0.8 \mathrm{~d}$. The net effect of these differences combined was a similar interovulatory period for the 2 production systems. The luteal cycle abnormality results show a higher than expected number of delayed ovulations type 2 (PCL2) for the high-concentrate cows.

\section{CONCLUSIONS}

Different production systems and specific levels of genetic merit for milk yield are commonly linked with varying levels of dairy cow fertility; particularly intensive systems and high genetic merit cows are implicated in decreasing fertility. Such conclusions are drawn from studies using different farms, breeds, or time periods and thus may be influenced by confounding between factors. In the study reported here, cows of known but differing genetic merit were kept under 2 contrasting production systems on the same farm at the same time, thus allowing conclusions to be drawn about the effects of system and genetic merit on fertility without such confounding. The number of cows was relatively small: a 200 -cow herd with 50 cows per genetic-line/production-system group. However, differences in fertility were found between genetic lines and between production systems, even in such a relatively small study. Some of these differences could be ascribed to differences in early-lactation energy balance, but not all. Genetic selection for high levels of fat and protein in milk increased the time taken to start luteal activity postpartum; a similar effect was found for days to first heat, even when the number of days to the start of luteal activity was taken into account. High genetic merit also increased the number of silent heats. All these effects would contribute to the increase in calving interval commonly found in national recording schemes. By contrast, differences in the time taken to start luteal activity after calving between the 2 produc- 
tion systems was entirely explained by energy balance characteristics of the systems.

Genetic selection for high productivity has been one reason for the decline in fertility in modern dairy herds, and a change in selection objectives to improve fertility is one way to reverse this trend. The incorporation of fertility characteristics in breeding value estimates and selection indices is one way to achieve this and has been implemented in several countries in recent years. Improving dairy cow diets in early lactation to encourage higher feed intakes and improve energy balance is another way forward. Alternatively, there is an argument toward less intensive systems and lower genetic merit for milk production to improve fertility. Any such approach requires a balanced economic view of the implications of these alternatives before a decision on the best way forward in any given situation is taken.

\section{ACKNOWLEDGMENTS}

This work was partly financed by Avoncroft Sires Ltd., BOCM Pauls Ltd., CIS, Cogent, Dartington Cattle Breeding Trust, Genus ABS, HUK, NMR, RSPCA, and Defra as part of RobustCow project in the Sustainable Livestock Production LINK program. The work was based on data collected under a grant from the Scottish Executive Environment and Rural Affairs Department. Ainsley Bagnall and other farm staff are thanked for taking milk samples for progesterone analysis.

\section{REFERENCES}

A.-Ranberg, I. M., B. Heringstad, G. Klemetsdal, M. Svendsen, and T. Steine. 2003. Heifer fertility in Norwegian dairy cattle: Variance components and genetic change. J. Dairy Sci. 86:2706-2714.

Beam, S. W., and W. R. Butler. 1999. Effects of energy balance on follicular development and first ovulation in post-partum dairy cows. J. Reprod. Fertil. Suppl. 54:411-424.

Butler, W. R., and R. D. Smith. 1989. Interrelationships between energy balance and postpartum reproductive function in dairy cattle. J. Dairy Sci. 72:767-783.

Coffey, M. P., G. C. Emmans, and S. Brotherstone. 2001. Genetic evaluation of dairy bulls for energy balance traits using random regression. Anim. Sci. 73:29-40.

Crawford, A. D., C. S. Mayne, M. A. McCoy, and D. Lennox. 2001. A comparison of the fertility of Holstein Friesian and Norwegian Dairy Cattle under low and high nutrient input systems. Page 217 in Proc. Br. Soc. Anim. Sci. Winter Meet. 2001.

de Vries, M. J., and R. F. Veerkamp. 2000. Energy balance of dairy cattle in relation to milk production variables and fertility. J. Dairy Sci. 83:62-69.

Diskin, M. G., D. R. Mackey, J. F. Roche, and J. M. Sreenan. 2003. Effects of nutrition and metabolic status on circulating hormones and ovarian follicle development in cattle. Anim. Reprod. Sci. 78:345-370.

Gilmour, A. R., B. J. Gogel, B. R. Cullis, S. J. Welham, and R. Thomson. 2002. ASReml user guide Release 1.0. VSN International Ltd., Hemel Hempstead, UK.

Hageman, W. H., G. E. Shook, and W. J. Tyler. 1991. Reproductive performance in genetic lines selected for high or average milk yield. J. Dairy Sci. 74:4366-4376.

Hare, E., H. D. Norman, and J. R. Wright. 2006. Trends in calving ages and calving intervals for dairy cattle breeds in the United States. J. Dairy Sci. 89:365-370.

Horan, B., J. F. Mee, M. Rath, P. O'Connor, and P. Dillon. 2004. The effect of strain of Holstein-Friesian cow and feeding system on reproductive performance in seasonal-calving milk production. Anim. Sci. 79:453-467.

Lamming, G. E., and D. C. Bulman. 1976. The use of milk progesterone radioimmunoassay in the diagnosis and treatment of subfertility in dairy cows. Br. Vet. J. 132:507-517.

Lamming, G. E., and A. O. Darwash. 1998. The use of milk progesterone profiles to characterise components of subfertility in milked dairy cows. Anim. Reprod. Sci. 52:175-190.

Langhill. 1999. Report from the Langhill Dairy Cattle Research Centre. Roslin, UK

Pryce, J. E., B. L. Neilson, R. F. Veerkamp, and G. Simm. 1999. Genotype and feeding system effects and interactions for health and fertility traits in dairy cattle. Livest. Prod. Sci. 57:193201.

Royal, M. D., A. O. Darwash, A. P. F. Flint, R. Webb, J. A. Woolliams, and G. E. Lamming. 2000. Declining fertility in dairy cattle: Changes in traditional and endocrine parameters of fertility. Anim. Sci. 70:487-501.

Royal, M. D., A. P. F. Flint, and J. A. Woolliams. 2002. Genetic and phenotypic relationships among endocrine and traditional fertility traits and production traits in Holstein-Friesian dairy cows. J. Dairy Sci. 85:958-967.

SAS Institute. 2004. The Statistical Analysis Software. SAS Institute, Cary, NC.

Simm, G. 1998. Genetic improvement of cattle and sheep. Farming Press, Ipswich, UK.

Veerkamp, R. F., G. Simm, and J. D. Oldham. 1995. Genotype by environment interactions: Experience from Langhill. Pages 5977 in Breeding and feeding the high genetic merit dairy cow. T. L. J. Lawrence, F. J. Gordon, and A. Carson. Br. Soc. Anim. Sci. Occ. Pub. No. 19.

Wall, E., S. Brotherstone, J. F. Kearney, J. A. Woolliams, and M. P. Coffey. 2005. Impact of non-additive genetic effects in the estimation of breeding values for fertility and correlated traits. J. Dairy Sci. 88:376-385.

Wall, E., S. Brotherstone, J. A. Woolliams, G. Banos, and M. P. Coffey. 2003. Genetic evaluation of fertility using direct and correlated traits. J. Dairy Sci. 86:4093-4102.

Westwood, C. T., I. J. Lean, and J. K. Garvin. 2002. Factors influencing fertility of Holstein dairy cows: A multivariate description. J. Dairy Sci. 85:3225-3237.

Wicks, H. C. F., A. F. Carson, M. A. McCoy, and C. S. Mayne. 2004. Effects of habituation to the milking parlour and reproductive performance of first calving Holstein-Friesian and Norwegian dairy herd replacements. Anim. Sci. 78:345-354.

Zurek, E., G. R. Foxcroft, and J. J. Kennelly. 1995. Metabolic status and interval to first ovulation in postpartum dairy cows. J. Dairy Sci. 78:1909-1920. 